\title{
CFD Analysis of airfoils with flaps for low Reynolds numbers
}

Manuscript template for the REPA Journal

William D. P. Fonseca 1,3 (D) orcid.org/0000-0001-5184-2193

Max W. F. Reis 1 orcid.org/0000-0002-3482-0854

Pedro F. L. Dias 2,3 orcid.org/0000-0002-5909-2363

Lourival M. S. Filho 2,3 orcid.org/0000-0001-5727-2427

\footnotetext{
${ }^{1}$ School of Mechanical Engineering, University of Campinas, Brazil

${ }^{2}$ State University of Maranhão, Brazil

${ }^{3}$ Laboratory of Modeling and Numerical Simulation, State University of Maranhão, Brazil

E-mail do autor principal: William Fonseca fonsecawdp@gmail.com
}

\section{ABSTRACT}

This paper presents a numerical investigation of the aerodynamic flow through airfoils with and without flaps for low Reynolds numbers. A two-dimensional, permanent, viscous model is adopted in the problem. The mass conservation and Navier-Stokes equations are discretized using two numerical methods, the panels method and the finite volume method, using CFD (Computational Fluid Dynamics) XFLR5 ${ }^{\circledR}$ and ANSYS Fluent ${ }^{T M}$ softwares. Initially, the work aims to compare the results obtained in the numerical simulation for different mesh refining with the analytical model available in the literature. Afterwards, it was verified how the pressure fields, velocity, current lines, drag and carry coefficients for symmetrical and asymmetrical airfoils work. Then, which airfoil is the most aerodynamically efficient, and finally, which numerical method is more feasible for twodimensional and incompressible aerodynamic simulations.

KEY-WORDS: Aerodynamics; Computational Fluid Dynamics; Flaps.

\section{RESUMO}

Este artigo apresenta uma investigação numérica do escoamento aerodinâmico através de aerofólios sem e com flap para baixo número de Reynolds. Um modelo bidimensional, permanente e viscoso é adotado no problema. As equações da conservação de massa e de Navier-Stokes são discretizadas utilizando dois métodos numéricos, o método dos painéis e o método dos volumes finitos, através dos softwares CFD (Computational Fluid Dynamics) XFLR5 ${ }^{\circledR}$ e ANSYS Fluent ${ }^{\mathrm{TM}}$. Inicialmente, 0 trabalho visa comparar o resultado obtido na simulação numérica para diferentes refinos de malha com o modelo analítico disponível na literatura. Posteriormente, busca-se verificar como se comporta os campos de pressão, velocidade, as linhas de corrente, os coeficientes de sustentação e arrasto para aerofólios simétricos e assimétricos. Em seguida, busca-se verificar qual aerofólio é mais eficiente aerodinamicamente, e por fim, averígua-se qual método numérico é mais viável para simulações aerodinâmicas bidimensionais incompressíveis.

PALAVRAS-CHAVE: Aerodinâmica; Dinâmica dos Fluidos Computacional; Flapes. 


\section{INTRODUCTION}

Due the continuous enhance in fossil fuels price, aerodynamic studies are conveniently encountered in order to develop better ways to decrease energy consumption of different transportation machines. Researches on models for calculating flows around aerodynamic surfaces has been growing exponentially in recent years, this can be credited to the application of these systems in many fields of engineering such as land vehicles, marine vehicles, turbomachinery and aircraft. Abbott and Von Doenhoff [1] comments that one of the main applications of aerodynamics is related with the aeronautic area, precisely with global design of airfoils. These equipments are defined by Anderson [2] as objects of aerodynamic profiles with constant and two-dimensional section.

The design of an airfoil seeks to support a situation where the aircraft is in prevailing flight, generally level, at cruising speeds and altitudes. However, circumstances such as takeoff and landing may render design conditions unsuitable for describing actual flight situations. In order to attend these different conditions, since the airplanes adopt hyperseting systems, like the flaps, defined by Brederode [3] as mechanical systems that change temporally the airfoil's geometry, in order to produce changes in the flow.

Due to the increasing technological importance of engineering airfoils, a number of tools have been developed gradually to analyze the aerodynamic behavior of these systems, among them the wind tunnel tests and computational simulations, better known as Computational Fluid Dynamics. The wind tunnel tests have some advantages over computational analysis, such as more precise specifications of the surrounding conditions, however, they are still time-consuming procedures with very high costs and also presents series of errors and uncertainties associated to the experiments that must be studied $[\mathbf{4 , 5}]$. Numerical methods, on the other hand, provide faster analysis and lower costs, mainly because of the processing power of digital computers, which makes CFD an important tool in modern aerodynamics.

According to Khayrullina et al., [6], among all the CFD methods encountered today, the most outstanding in the aeronautics industry are the Panels Method and the Finite Volume Method. The Panels Method solves the non-viscous flow by the Laplace equation, distributing singularities 94 (elemental flows) along the body that satisfy the impermeability condition (the flow cannot pass through a solid non-porous surface) and the Kutta Condition [7]. The Finite Volumes Method consists in integrate differential conservation equations. For this, the solution domain is divided into a number of control volumes, and the conservation equation is applied to each of these volumes [8]. Wang [7] affirms that the computational nodes are located in the center of the control volumes and the variables values can be found in the volume boundary by interpolation of the nodal results. As a result, it is obtained an algebraic equation for each volume.

The present work aims to numerically analyze the flow and the aerodynamic characteristics in two airfoils, one being symmetrical and the other asymmetrical with the presence of flaps. The work also aims to compare which numerical method (Panels Method or Finite Volumes) is more feasible and present results closer to those presented in the literature. For that, the simulations were carried out with software's that use such methods in their source algorithms.

\section{LITERATURE REWIEW}

\subsection{Panels Method}

According to Silva [9] the utilization of analytical theories in aerodynamic analysis, as Conformal Transformation, are extremely painful for arbitrary geometry bodies, since the high level complexity of the algebraic manipulation. In this kind of application the numerical methods present their advantages, once they can be applied for all geometries, except in specific restrictions.

There is a class of numerical methods very used in aerodynamic which are based in the discretization of the boundary surfaces. These methods are called Boundary Elements Method [10] and one of them is the Panels Method, very used in the aeronautic industry to the analyses of potential flows through blunt bodies.

Many authors, as Barrett et al., [11] and Kier et al., [12], consider that the first steps in the development of the Panels Method were given by Martensen [13]; Hess and Smith [14], which describe a way of analyzing aerodynamic profiles in potential flows. Such a method allows a wide variety of choice of singularities and their forms of distribution on the discretized surface of the body. A comparative study of these possibilities can be seen in Pereira et al [15]. 
According to Lafaete Jr. [16], the panels method presents a simple and computationally inexpensive way of calculating the aerodynamic performance. Basically, this method divides the flow into flat plates, calculates the velocities of the flow in these plates and, from there, obtains the pressures along the profile, allowing the evaluation of the aerodynamic forces.

Lafaete Jr. [16] affirms that the calculation of the tangential and normal velocities of the circudating flow over the airfoil in each panel is given by the Equations (1) and (2).

$$
\begin{aligned}
& u_{i}=v_{\infty} \operatorname{sen} \alpha+\sum_{j=1}^{N} q_{j} u_{s i j}+\gamma \sum_{j=1}^{N} u_{v i j} \\
& v_{i}=v_{\infty} \operatorname{sen} \alpha+\sum_{j=1}^{N} q_{j} v_{s i j}+\gamma \sum_{j=1}^{N} v_{v i j}
\end{aligned}
$$

Where, $u i$ is the tangential velocity and $v i$ the normal velocity of the panel, $\alpha$ is the angle of attack, $q j$ e $\gamma$, are the singularities intensity of the sources and vortices, respectively. After the calculation of the velocities, the Bernoulli's principle is applied in relation with the flow in the infinity in order to obtain the pressure distribution:

$$
\frac{p_{i}}{\rho_{i}}+\frac{u_{i}^{2}}{2}=\frac{p_{\infty}}{\rho_{\infty}}+\frac{v_{i}^{2}}{2}
$$

At least, applying these pressures on the panel area, it is obtained the decomposed lift and drag forces, expressed by Anderson [2] in Equations (4) and (5).

$$
\begin{array}{r}
F_{L}=\int_{A} d F_{L}=-\int_{A}\left(p_{i} \operatorname{sen} \alpha+\tau \cos \alpha\right) d A \\
F_{D}=\int_{A} d F_{D}=\int_{A}\left(-p_{i} \cos \alpha+\tau \operatorname{sen} \alpha\right) d A
\end{array}
$$

Where, $p_{i}$ is the normal pressure and $\tau$ the shear pressure of the panel.

This method presents a good approximation for the lift forces, which varies very little with the number of panels adopted. However, the drag has a decreasing behavior as the number of panels increase, which induces a fixed number of panels in order to realize a comparison among profiles, turning the errors systematic, capable of representing a real trend, although absolute values have questionable reliability [17].

\subsection{Finite Volumes Method}

The Finite Volumes Method, described in detail by Patankar [18], consists in dividing the domain in a number of non-overlapping control volumes, such that each control volume contains one point of the mesh. A unique equation is then integrated into each control volume.

The discretized equation expresses the properties conservation principles for a finite control volume. The most attractive feature of finite volumes formulation is that the resulting solution implies that the integral conservation of quantities such as mass, momentum and energy is satisfied over any group of control volumes and, obviously, over the entire computing domain. This feature exists for any number of mesh points, not only in the limit case, when the number of mesh points becomes very large. Thus, even for a coarse mesh, the solution exhibits an accurate integral balance.

The governing equations that modulates the aerodynamic flow around bodies are the mass conservation and Navier-Stokes equations. In this, the region of the boundary layer was modeled numerically with a greater degree of refinement of the mesh in region near the surface. These equations are expressed in vector form, for a twodimensional, incompressible and steady-state flow, as follows:

$$
\begin{aligned}
& \nabla \bullet \vec{V}=0 \\
& \rho \frac{D \vec{V}}{D t}=-\nabla p+\rho \vec{g}+\mu \nabla^{2} \vec{V}
\end{aligned}
$$

In these equations, $\vec{V}$ indicates the free flow velocity of the flow, $\rho$ the density, $p$ the pressure, $g$ the gravity and $\mu$ the dynamic viscosity.

Due to the nonlinearities present in the linear momentum conservation equations and the strong pressure, velocity coupling, it is necessary to use iterative strategies for the numerical solution of problems. An alternative is to use the SIMPLE (Semi Implicit Linked Equations) algorithm, Maliska [19] affirms that it consists of two distinct steps: in the first, the velocities are corrected to 
satisfy the continuity equation, and in the second, the Pressures are advanced to complement the iterative cycle.

\section{MODELING AND SIMULATION}

\subsection{Description}

The computational methodology presented in this work involves the solution of the external flow. The simulations were carried out with the external isothermal air flow, where the solutions of the equations presented in section 3 necessary to obtain the results of the interaction between the fluid and the airfoil were realized with the aid of the Computational Fluid Dynamics software XFLR5 ${ }^{\circledR}$ and ANSYS Fluent ${ }^{\mathrm{TM}}$.

\subsection{Modeling using XFLR5}

According to Katz and Plotkin [20], in the Panels Method, the body surface is discretized into small, straight or curved segments, called panels. The starting and ending points of each panel are called nodes, or nodal points, and the center point is called the control point. On the panels are distributed singularities such as fountains, dipoles or vortices. In this way, the boundary conditions are imposed only at the control points of the panels.

The discretization of the models used in this work were performed using the XFoil code through XFLR5 ${ }^{\circledR}$ software version 6.99 . This code is extremely used to evaluate aerodynamic characteristics of airfoils and finite wings, and these can occur through several numerical methods, such as LLT (Lifting Line Theory), VLM (Vortex Lattice Method) and 3D Panels. In this analysis, a two-dimensional body (airfoil) was discretized by the panel's method. 800 straight panels were used along the surface of the body, on which vortices were distributed. The initial conditions used in the present work were inserted into the software to simulate flow conditions such as laminar and incompressible. These were the Reynolds number and the Mach number equal to $\mathrm{Re}=102$ and $\mathrm{Ma}=0.0578$.

\subsection{Modeling using ANSYS Fluent ${ }^{\mathrm{TM}}$}

\subsubsection{GEOMETRY GENERATION}

The geometries were created using the commercial software Autodesk Inventor ${ }^{\mathrm{TM}}$. Such a choice was based on the easy way when using he 2D modeling tools. For the analysis of fluid dynamics of the external flow, the ANSYS Fluent ${ }^{T M}$ version 16.0 software was used. Thus, a solid and closed model was created and this was subtracted from within the body volume, thus generating the geometry submitted to the flow. Positioning the geometry within this volume could simulate the actual conditions of interaction between the body and the fluid. This geometry gives the name of the computational domain. The geometries used in the simulations were the NACA 0012 and Eppler 423 airfoils, where the flap was housed at $20 \%$ of the trailing edge with deflection of $50^{\circ}$. This deflection was simulated because of the greater efficiency of an airfoil with flap being between $40^{\circ}$ and $60^{\circ}$ [2].

\subsubsection{MESH GENERATION AND COMPUTATIONAL METHODOLOGY VALIDATION}

The mesh generation comprises the process of decomposition of the total volume into smaller volumes, allowing the use of the finite volume method to solve the differential equations that govern the problem. In this work, an analysis of the dependence of the computational mesh was made, where we tried to ascertain the refining of this influence in the results when these are compared with those presented in the literature. For the study, three mesh refinement cranes were used, and the meshes generated in the model have unstructured characteristics with triangular volumes. Figures $1(a-c)$ show the aspects of the meshes generated, while Table (1) explains the number of nodes of each mesh and their respective orthogonal qualities.

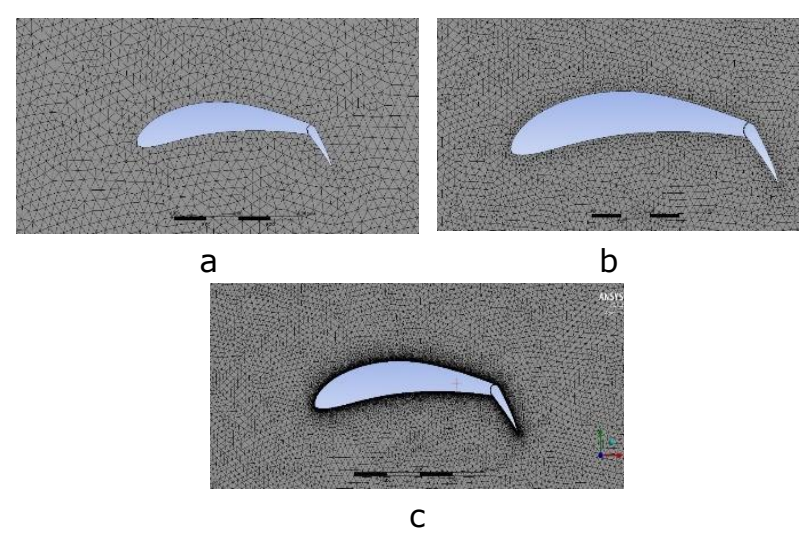

Figure 1: Computational mesh generated. 
Table 1: Mesh number of nodes.

\begin{tabular}{c|c|c}
\hline & $\begin{array}{c}\text { NUMBER OF } \\
\text { NODES }\end{array}$ & $\begin{array}{c}\text { MAXIMUM } \\
\text { ORTHOGONAL } \\
\text { QUALITY }\end{array}$ \\
\hline $\begin{array}{c}\text { Figure 4.a } \\
\text { refined mesh }\end{array}$ & 89551 & $89,75 \%$ \\
\hline $\begin{array}{c}\text { Figure 4.b } \\
\text { intermediate } \\
\text { refinement }\end{array}$ & 76282 & $72,74 \%$ \\
\hline $\begin{array}{c}\text { Figure 4.c } \\
\text { coarse mesh }\end{array}$ & 19703 & $53,35 \%$ \\
\hline
\end{tabular}

The results of the comparative analysis of the models presented previously with the experimental data exposed by Abbott [21] (Figure 2) showed that there is a high discrepancy when using the mesh without refinement, it was soon found that the larger the number of elements, the more approximate are the numerical results of the experimental ones. In this way, it was decided to use the refined mesh for simulations.

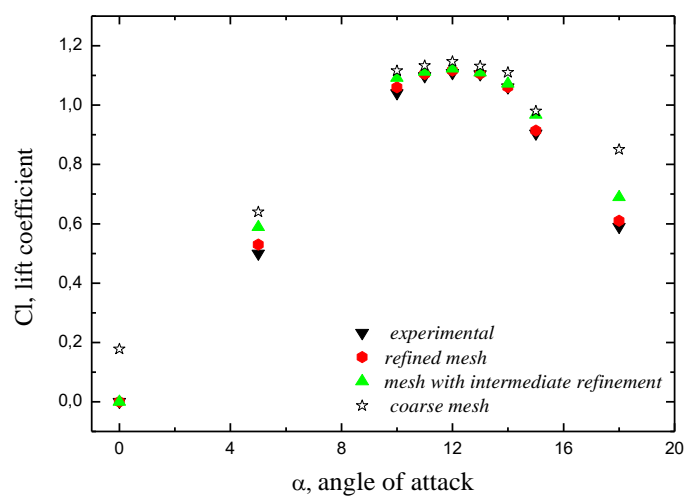

Figure 2: Comparison among different mesh results.

\subsubsection{BOUNDARY CONDITIONS}

The boundary conditions were sized to simulate the real flow conditions. The contour conditions used in the model are presented in Table (2). These conditions were obtained from the Fluent [22] tutorial.
Table 2: Boundary Conditions.

\begin{tabular}{c|c|c}
\hline PLACE & NOMENCLATURE & VALUES \\
\hline $\begin{array}{c}\text { Computational } \\
\text { domain input }\end{array}$ & Prescribed velocity & $10 \mathrm{~m} / \mathrm{s}$ \\
\hline $\begin{array}{c}\text { Superior part of } \\
\text { the computational } \\
\text { domain }\end{array}$ & Prescribed velocity & $10 \mathrm{~m} / \mathrm{s}$ \\
\hline $\begin{array}{c}\text { Inferior part of the } \\
\text { computational } \\
\text { domain }\end{array}$ & Prescribed velocity & $10 \mathrm{~m} / \mathrm{s}$ \\
\hline $\begin{array}{c}\text { Computational } \\
\text { domain output }\end{array}$ & Prescribed pressure & $1 \mathrm{~atm}$ \\
\hline Airfoil & Wall & $0 \mathrm{~m} / \mathrm{s}$ \\
\hline
\end{tabular}

\section{RESULTS}

\subsection{Airfoils without flaps}

Figures $3(a-c)$ show the pressure fields of the airfoil NACA 0012 with different angles of attack, $0^{\circ}, 10^{\circ}$ and $15^{\circ}$, respectively. It is observed there is a symmetry in the pressure field in Figure 3.a, and the stagnation points are located on the leading and trailing edges. This result was expected since, according to Çengel and Cimbala [23], there are no pressure gradients for symmetrical airfoils subjected to flow with zero angles of attack. As the angle of attack increases, the pressure gradient becomes favorable $(\partial \mathrm{P} / \partial \mathrm{x}<0)$ in the upper part of the profile and adverse $(\partial \mathrm{P} / \partial \mathrm{x}>0)$ in the lower part, Figures 3.b and 3.c, this is a consequence of the displacements of the stagnation points.

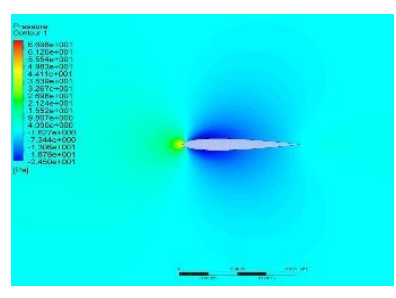

a

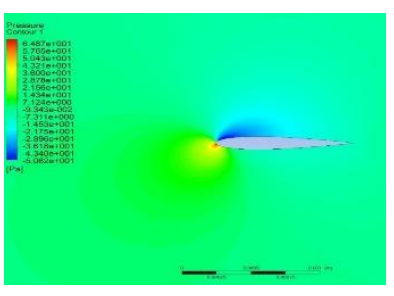

b 


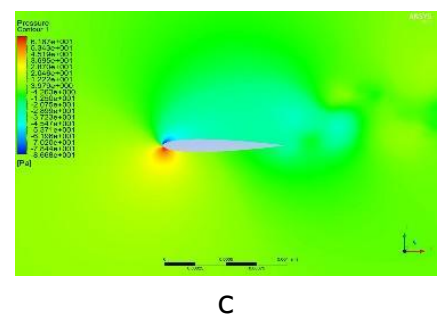

Figure 3: Airfoils without flaps - Pressure field.

This aspect of the pressure field extends until approximately $15^{\circ}$, where it is perceived that the separation of the boundary layer inverts the pressure field, being this phenomenon a consequence of the formation of vortices in the wake of the flow. Figure 4 (a-d) shows the boundary velocity fields and the flow lines, where the laminar separation of the boundary layer occurs.

The pressure difference in Figs. (3.b) and (3.c) give rise to lift and a linear curve is generated up to the angle of $15^{\circ}$. After this angle there is an abrupt decrease in the coefficient of lift, this is a result of the separation of the boundary layer already explained. Figure 5 shows and compares the curve of this aerodynamic parameter with Abbott [21].

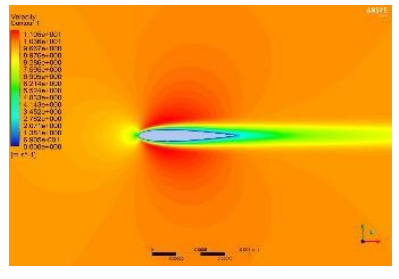

a

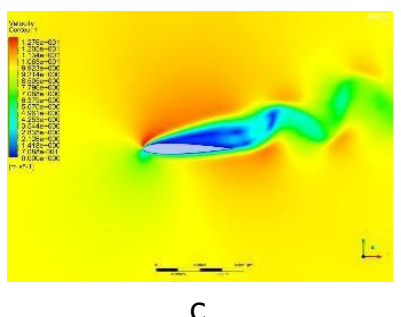

C



b



Figure 4: Airfoils without flaps - Velocity Field.

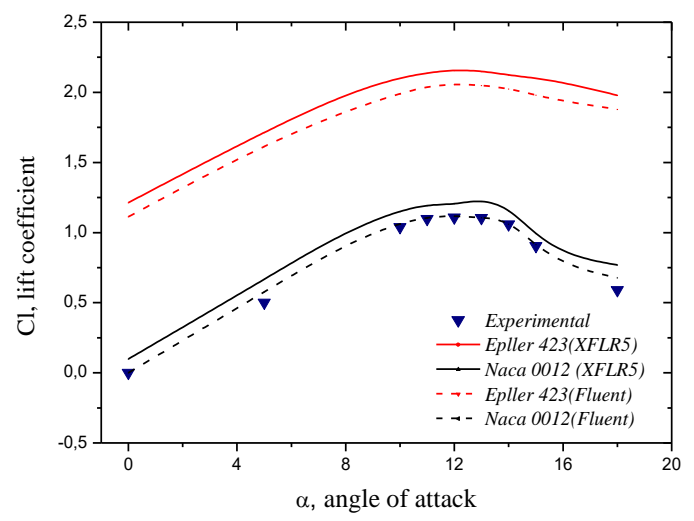

Figure 5: Airfoils without flaps - Lift coefficients.

Another analysis that can be obtained from this result is the difference of the coefficients for the two numerical methods used in the simulation. It is verified that the finite volumes method has results closer to the experimental ones, presented in Abbott [21], this is because the computational mesh scheme used by this software. Thus, there is a $12 \%$ error between the simulated results for the FVM (Fluent ${ }^{T M}$ Software and the panels method XFLR5 $\left.{ }^{\circledR}\right)$.

For the asymmetrical profile Eppler 423 , it is noticed that even with no angle of attack it is generated lift coefficients of this profile are superior to the one of the symmetrical airfoil studied, this is due to its camber (curvature). However, the stall of this profile occurs at angles lower than the airfoil NACA 0012, this is because the geometry of the asymmetric profile. According to $\mathrm{Xi}$ et al [24] this leads to the faster transition of the boundary layer.

With respect to the drag of these profiles, Figure 6 shows that up to $14^{\circ}$ the values are approximate, however above this angle the NACA 0012 airfoil grows more sharply than the Eppler 423. It is also noticed that the error associated with the difference of the numerical method used persists, that is, it is stall $12 \%$. 


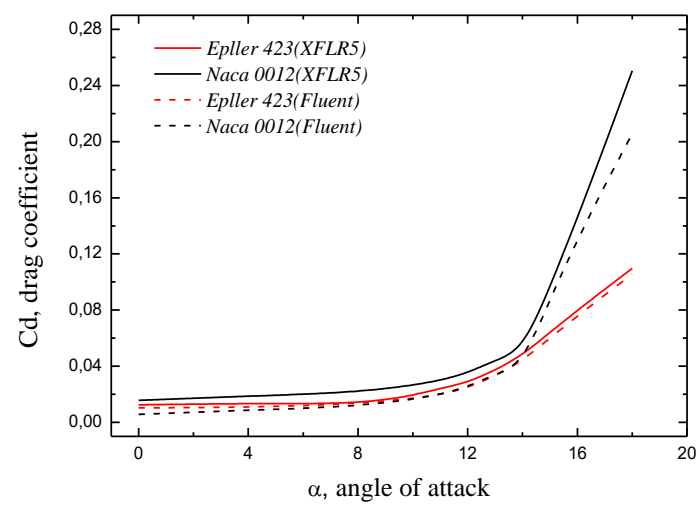

Figure 6: Airfoils without flaps - Drag coefficients.

Analyzing the flap with airfoils, it was found that even at low angles of attack the pressure difference between the upper and lower surfaces of the profiles is very large - Figures $7(a-c)$. This causes high values in the lift coefficients.

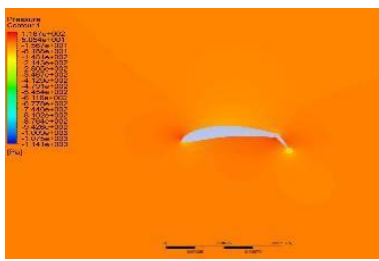

a

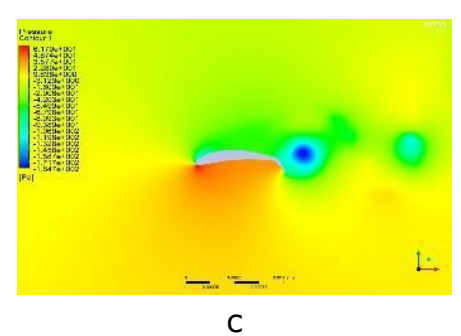

C

Figure 7: Airfoils with flaps - Pressure field.

It can also be noted that the stall in the airfoil with flap occurs at angles lower than the airfoil without flap, such phenomenon is based on the excessive presence of vortices in airfoils with flaps at low angles, as observed at the field velocity of Figures $8(a-c)$. Figure 9 graphically indicates the phenomenon.

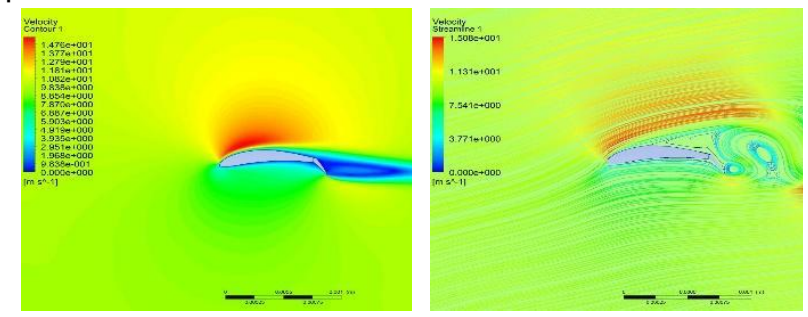

a

b

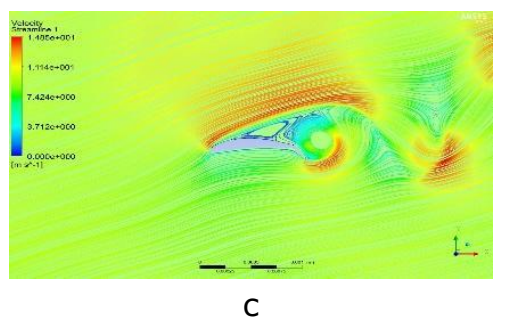

Figure 8: Airfoils with flaps - Velocity field.

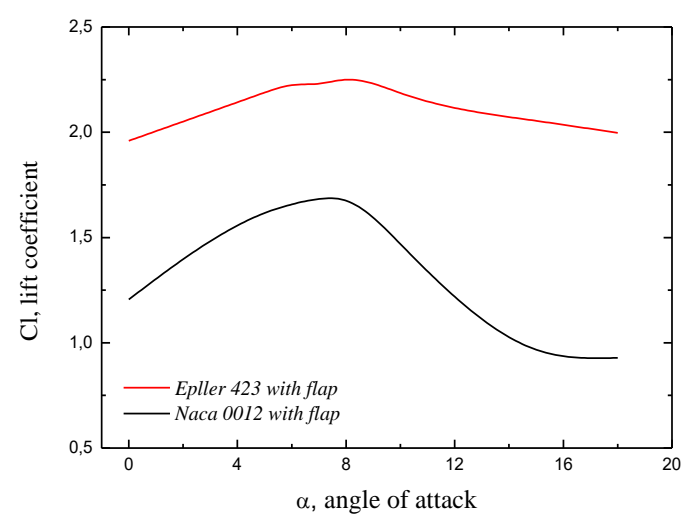

Figure 9: Airfoils with flaps - Lift coefficients (obtained in Fluent).

About the drag, Figure 10 shows that the symmetrical airfoil has smaller values for small angles of attack. However, for angles above $10^{\circ}$ this has coefficients greater than those presented by the asymmetric profile.

After all simulations, it was observed from Figure 11 that the asymmetrical Eppler 423 flaps airfoil is the one with the highest aerodynamic efficiency for all angles of attack studied. This is because this profile has better CL/CD ratios for all simulated angles.

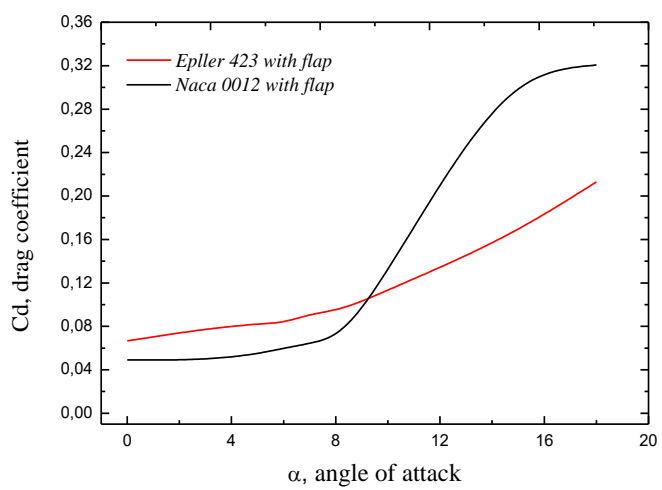

Figure 10: Airfoils with flaps - Drag coefficients (obtained in Fluent). 


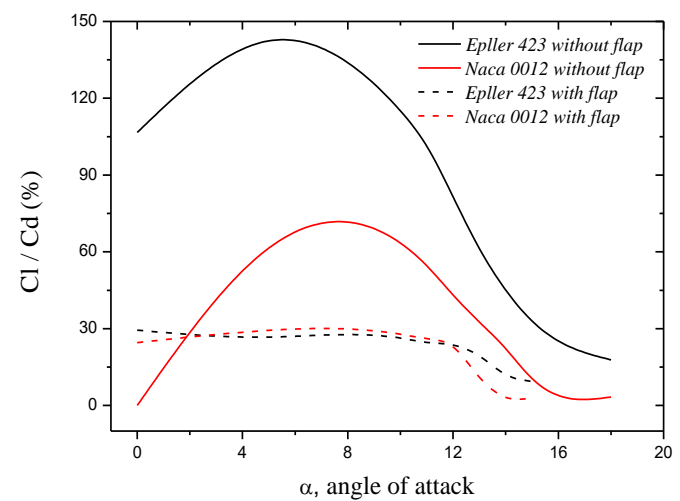

Figure 11: Airfoil's aerodynamic efficiency (obtained in Fluent).

\section{CONCLUSION}

In this work, the aerodynamic characteristics of airfoils with and without flaps were studied through Computational Fluid Dynamics, the Reynolds number was fixed and the angle of attack varied in order to verify which airfoil and its availability (without or with flap) would be more aerodynamically efficient. It was also studied which numerical method (Finite Volumes or Panels) is more feasible for the realization of two-dimensional simulations in incompressible aerodynamics.

From the results presented in the previous chapters, we arrive at some conclusions:

The simulations showed that when analyzed only the airfoils without flap, the asymmetric one has superior lift coefficient and drag coefficients similar to those presented by the symmetrical profile.

When flap profiles were evaluated, it was verified that the asymmetric in the same way as when the flaps ones had better $\mathrm{CL} / \mathrm{CD}$ ratios than the symmetrical airfoils. However, it was also found that the stall for the profiles with flap occurs at angles lower than those without it.

It is also concluded that the Eppler 423 profile without flap is the one with the highest efficiency, since this airfoil is the one with the best CL/CD ratio. However, this profile goes into stall at smaller angles than the symmetrical airfoil studied.

Finally, it was observed that Fluent ${ }^{\mathrm{TM}}$ software (finite volume method) has a greater robustness with aerodynamic analysis when compared to XFRL5 $^{\circledR}$ (panels method). However, it requires a higher computational cost.

\section{REFERÊNCIAS}

[1] Abbott I. H; Von Doenhoff A. E. Theory of wing sections, including a summary of airfoil data. New York: Dover Publications, 1959.

[2] ANDERSON JR, J. D. Fundamentals of aerodynamics. 5. ed. Nova York: Mcgrauw-Hill, 2007. p.1131.

[3] BREDERODE, V. de. Aerodinâmica incompressível: Fundamentos. Lisboa: IST Press, 2014. P.735.

[4] ROGERS, S.; ROTH, K.; NASH, S. CFD validation of high-lift flows with significant windtunnel effects. In: APPLIED AERODYNAMICS CONFERENCE, 18., 2000, Denver. Procedeeng... Denver, 2000.

[5] JOHNSON, F. T.; TINOCO, E. N.; YU, N. J. Thirty years of development and application of CFD at Boeing Commercial Airplanes. Computers \& Fluids, Seattle, v. 34 , n. 10 , p. 1115-1151, 2005.

[6] KHAYRULLINA, A. et al. CFD simulation of train aerodynamics: train-induced wind conditions at an underground railroad passenger platform.

Journal of Wind Engineering and Industrial Aerodynamics, v. 139 , p. $100-139$, 2015. DOI: 10.1016/j.jweia.2015.01.019.

[7] WANG, H. B et al. Influence analysis of propeller location parameters on wings using a panel/viscous vortex particle hybrid method. The Aeronautical Journal, v. 122, n. 1247, p.21-41, 2018.

[8] SHARBATDAR, M.; OLLIVIER-GOOCH, C. Adjoint-Based Functional Correction for Unstructured Mesh Finite Volume Methods. Journal of Scientific Computing, v. 76, n. 1, p.1-23, 2018.

[9] SILVA, D. F. C. Simulação Numérica Do Escoamento Ao Redor De Aerofólios Via Método De Vórtices Associado Ao Método Dos Painéis. 2005. Dissertação (Mestrado em Engenharia Mecânica)- Universidade Federal do Rio de Janeiro, Rio de Janeiro, 2005.

[10] BREBBIA, C. A.; TELLES, J. C. F.; WROBEL, $L$. C. Boundary Element Techniques: Theory and Applications in Engineering. Berlin; Heidelberg: Spring-Verlag, 1984.

[11] BARRETT, R.; ANDREW N. Comparison of airfoil precomputational analysis methods for optimization of wind turbine blades. IEEE

Transactions on Sustainable Energy, v. 7, n 
.3, p. 1081-1088, 2016.

[12] KIER, T. M.; MARK J. V; CHRIS W. B. Integrated flexible dynamic loads models based on aerodynamic influence coefficients of a $3 . d$ panel method. Proceedings of the IFASD, 2015.

[13] MARTENSEN, E. The Calculation of the Pressure Distribution on a Cascade of thick Airfoils by means of Fredholm Integral Equations of the Second Kind. Göttingen: Aerodynamics Experimental Station, 1959.

[14] HESS, J. L; SMITH, A. M. Calculation of non-lifting potential flow about arbitrary threedimensional bodies. Progress in Aerospace Sciences, v. 8, p. 1-138, 1967.

[15] PEREIRA, L. A.; HIRATA, M. H.; MAZANARES, N. Wake and Aerodynamics Loads in Multiple Bodies-Application to Turbomachinery Blade Rows. Journal of Wind Engineering and Industrial Aerodynamics, v. 92, pp. 477-491, 2004.

[16] LAFAETE JR. Otimização do arqueamento de dm aerofólio utilizando ligas dom memória de forma. 2013. Dissertação (Mestrado em Engenharia Mecânica) Universidade Federal do Rio de Janeiro, Rio de Janeiro, 2013.

[17] LIMA, J. S. B. Implementação Numérica do Método dos Painéis Estudo de Características Aerodinâmicas de Aerofólios. São Paulo: Novas edições acadêmicas, 2016.

[18] PATANKAR, S.V. Numerical Heat Transfer and Fluid Flow. Boca Raton: Hemisphere Publishing, 1980.

[19] MALISKA, C. R. Transferência de Calor e Mecânica dos Fluidos Computacional. 2. ed. São Paulo: LTC., 2004. p. 453.

[20] KATZ, ].; PLOTKIN, A. Low Speed Aerodynamics. 2. ed. Cambridge: Cambridge University Press, 2001.

[21] ABBOTT, I. H. The Drag of Two Streamline Bodies as Affected by Protuberances and Appendages. NACA Report, n. 451, p. 171-176, 1932.

[22] FLUENT v6. 3. Fluent Incorporate Inc., Centerra Resource Park, 10, Cavendish Court, Lebanon, New Hampshire, USA, 03766, 2006.
[23] ÇENGEL, Y. A.; CIMBALA, J. M. Mecânica dos fluidos: Fundamentos e Aplicações. São Paulo: McGrauw-Hill, 2007. p. 816.

[24] XI, H. et al. Numerical simulation of gurney flaps lift-enhancement on a low Reynolds number airfoil. Science China, China, v. 60, n. 10, p. 1548 - 1559, Oct. 2017. 